\title{
Gravidez na adolescência: situação atual
}

\section{Pregnancy in adolescence: current situation}

A adolescência, segundo a Organização Mundial da Saúde (OMS), deve compreender o período que abrange dos 10 aos 19 anos, estratégia que permite melhores comparações de dados, embora esteja claro que tanto os limites inferiores como os superiores variem individual e culturalmente. Por ser um período muito especial para a construção do indivíduo e para sua inserção social, deve ser entendido como de risco e vulnerabilidade ${ }^{1}$.

O conceito de risco, anteriormente considerado apenas como biológico e médico, amplia-se para introduzir maior abrangência, envolvendo aspectos de naturezas social e comportamental. Associa-se naturalmente ao conceito de vulnerabilidade, à maior probabilidade de dano individual e social, e introduz o mecanismo de prevenção, ou seja, de proteção contra fatores que podem alterar para pior a qualidade de vida individual, familiar e da comunidade ${ }^{2}$.

A gravidez na adolescência, habitualmente, é considerada de risco, perigosa, inapropriada e inadequada para os interesses dos jovens, particularmente por afetar preferencialmente meninas que vivem na pobreza, em países pouco desenvolvidos ${ }^{3}$. Embora as taxas de fertilidade neste período, ao contrário do que se afirma em muitos trabalhos, estejam decrescendo em perspectiva global, aproximadamente 18 milhões de meninas abaixo de 20 anos dão à luz a cada ano ${ }^{4}$. Dois milhões delas estão com menos de 15 anos $^{5}$. Uma das razões que poderiam explicar tais números exuberantes está na constatação de que, na história da humanidade, esta é a maior coorte de adolescentes e jovens de todos os tempos.

Numericamente falando, embora as taxas de fertilidade estejam diminuindo em todo o mundo desenvolvido, não se pode perceber a mesma tendência neste enorme grupo etário, o qual aumenta especialmente em países do Sul da Ásia e em regiões subsaarianas. Nestes países em desenvolvimento, onde são altos os índices de pobreza, dificilmente a gravidez adolescente é acidental, resultante de apenas da experimentação sexual ${ }^{2}$. Frequentemente, as meninas são induzidas ao casamento muito cedo e encorajadas a ficarem grávidas o mais rápido possível, uma vez que a maioria é desprovida de perspectivas pessoais futuras e não conhece outra vida — ou valor pessoal — , que não esteja centrada na maternidade. A pobreza, associada ao baixo nível de escolaridade, são dois fatores que estão intrinsecamente Faculdade de Ciências Médicas da UNICAMP Cidade Universitária Zeferino Vaz - Barão Geraldo CEP: 13083-881 Campinas (SP), Brasi

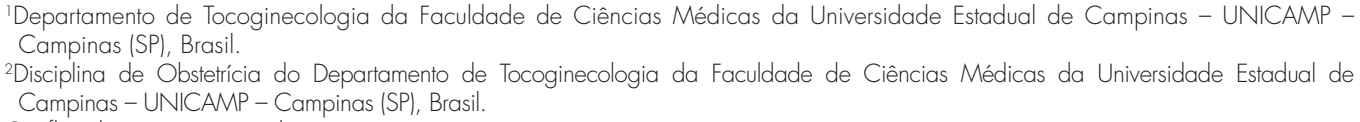


entrelaçados, o pano de fundo da maioria destes países, em que o panorama da gravidez precoce se repete na contramão da maior parte dos que estão no mundo desenvolvido. Qualquer que seja o estado civil da adolescente, a maioria é pobre ou sem fontes adequadas, tais como o suprimento de sobrevivência, algumas porque são solteiras e/ou ainda estão na escola, outras porque estão casadas, mas com pouco ou nenhum controle do orçamento familiar, não trabalham ou têm salários extremamente baixos. No Brasil, os dados não têm se mostrado diferentes, desenhando-se o mesmo cenário que se identifica em outros países, sendo mais marcantes em algumas regiões e grupos sociais, principalmente os mais pobres e com níveis educacionais mais baixos.

Como um todo, entretanto, o Brasil acelera a redução da gravidez na adolescência. O número de partos entre 10 a 19 anos, atendidos pelo Sistema Único de Saúde (SUS), reduziu-se em mais de 22,0\% na segunda metade da década passada, e entre 2000 e 2009, após diminuição de 15,6\% na primeira metade, decresceu 34,6\% em todo o período (Figura 1). A maior redução no número de partos, nos último cinco anos, ocorreu nas regiões Nordeste $(26,0 \%)$ e Centro-Oeste (24,4\%), e abaixo da taxa média nas regiões Sudeste $(20,7 \%)$, Sul $(18,7 \%)$ e Norte $(18,5 \%)^{6}$.

Do mesmo modo, podem ser analisados os dados norte-americanos: houve declínio contínuo e consistente entre 1991 e 2005, com recuperação transitória entre 2007 e 2009, correspondendo a 0.5 por 1.000 , entre 10 e 14 anos, e 39,1 por 1.000 , entre 15 e 19 anos, respectivamente ${ }^{7}$.

A gravidez em tal período mostra-se, portanto, como um problema não resolvido nos países em desenvolvimento e em alguns dos chamados desenvolvidos. O conceito prevalente é de que sua maior importância reside nos aspectos sociais relacionados, e não nos biológicos ou médicos como se acreditava anteriormente, que se aceita de modo equivocado até atualmente.

A fecundidade adolescente pode ser considerada um dos melhores indicadores da qualidade de saúde de um país moderno. Nos países em desenvolvimento, observa-se, na faixa etária, a expectativa em seguir os padrões de comportamento sexual dos desenvolvidos, sem a contrapartida necessária do oferecimento de níveis de educação adequados e serviços de atenção e assistência semelhantes e absolutamente necessários ${ }^{8}$. Pode-se reconhecer a ignorância dos pais, professores e adolescentes sobre sexualidade e reprodução, o que aumenta os índices de iniciação sexual precoce, sem adequada proteção e que resulta em gravidezes indesejadas. A pobreza extrema que se repete nos filhos de adolescentes são fatores de risco para a repetição do modelo.

Em um passado não muito distante e em alguns contextos sociais e em algumas culturas, como já se comentou, a gestação no início do período reprodutivo era encarada como normal e até mesmo desejável. Eram diferentes as expectativas em relação ao papel da mulher, particularmente da mulher adolescente, do que se pretende e se sanciona como legítimo na sociedade hodierna. A sexualidade e a reprodução encontravam-se indissoluvelmente unidas, e o exercício destas 'funções' obedecia a um intervalo extremamente breve de espera para se cumprir integralmente, uma vez que a

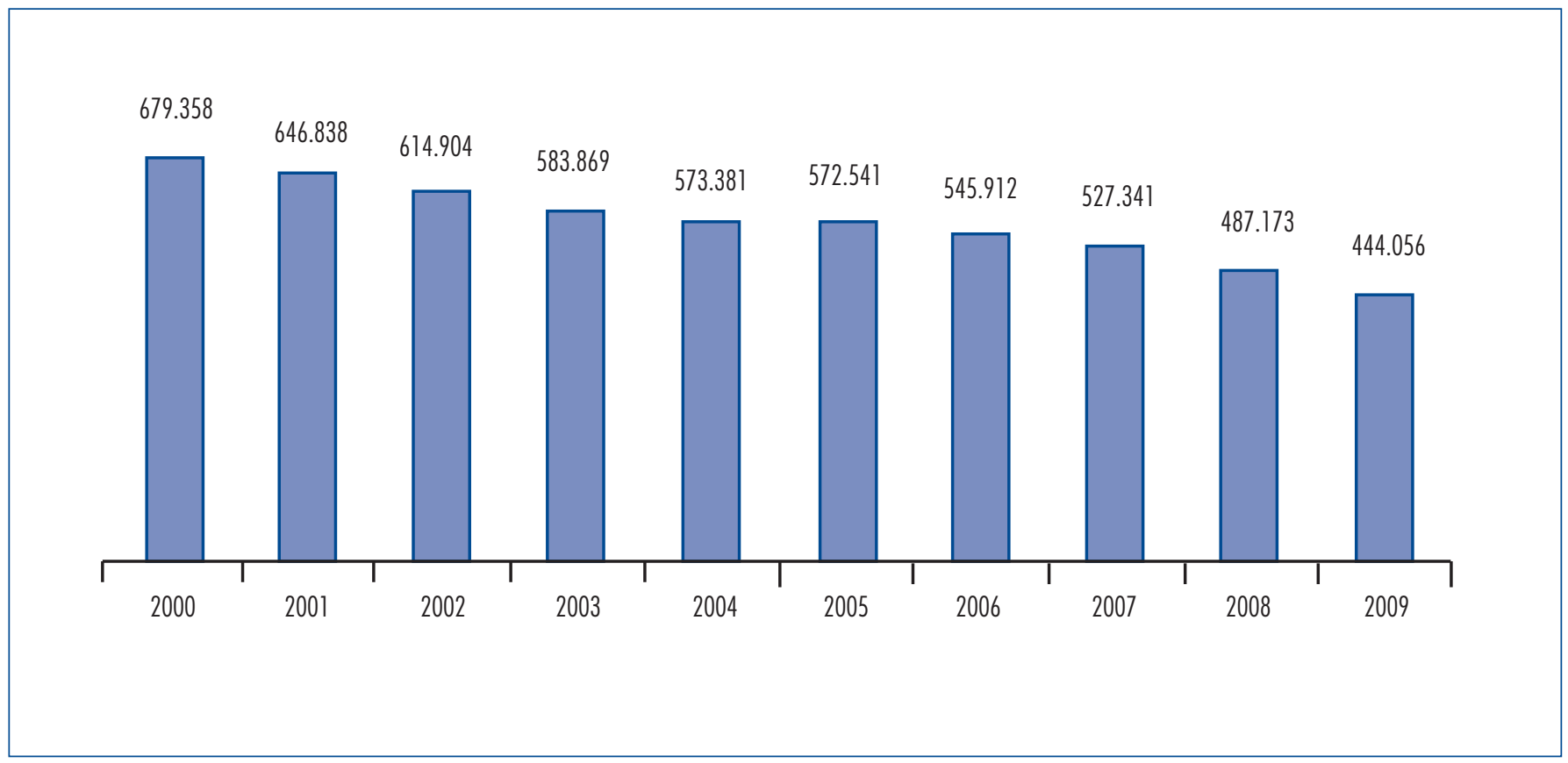

Figura 1. Evolução do número de gestações em adolescentes entre 2000 a 2009 no Brasilb. 
'obrigação' reservada à mulher era unicamente a de ser esposa e mãe — nesta ordem. Com o passar dos anos, o período entre o amadurecimento sexual e o casamento (tempo de iniciação sexual adequado para a formação da família consentâneo ao consentimento social) foi ficando mais ampliado, uma vez que mais precocemente se instalam a menarca e a espermarca e cada vez mais tardiamente se realiza o casamento formal, por se ampliarem as oportunidades disponíveis de educação e profissionalização, principalmente para adolescentes do sexo feminino.

O exercício da vida sexual, outrora confinado aos limites do casamento, transfere-se para esse intervalo alongado e aflora com uma intensidade jamais vista, estimulado por elementos de formulação de comportamentos e atitudes (mídias), dirigidos especialmente para este segmento populacional. Outras variáveis não menos determinantes relacionadas são a conquista e a difusão dos métodos contraceptivos, combinadas a um processo de urbanização das populações, o esgarçamento e a fragilização da rigidez da tutela familiar sobre o comportamento sexual dos filhos e a grande diversificação dos papéis e interesses de diferentes atores sociais.

Muitas das discrepâncias que se encontram nesta discussão devem-se a critérios diferentes utilizados por vários estudos avaliados para definições e conceitos, devido a métodos inadequados usados para interpretar os fenômenos, à habitual falta de controle de variáveis confundíveis, às amostras insuficientes e não controladas e à generalização dos resultados, quase sempre imprecisos e tendenciosos.

Neste contexto está baseada a existência de desvantagens para a saúde de gestantes adolescentes e seus filhos, atribuída à condição biológica de imaturidade, significativamente mais presente em comparação aos resultados encontrados para mulheres adultas, entre 20 e 30 anos, reconhecidamente o período mais apropriado para a maternidade em todas suas dimensões. Entretanto, está cada vez mais claro que as complicações encontradas associam-se a múltiplos fatores de índole não médica, como idade, paridade, assistência pré-natal inexistente ou de baixa qualidade, estado geral nutricional deficiente, doenças associadas à pobreza, além de fatores sociais e culturais ${ }^{8}$.

As doenças maternas mais citadas, como pré-eclâmpsia, anemia, prematuridade e baixo peso ao nascer (BPN), parecem estar mais fortemente associadas às condições psicossociais altamente desfavoráveis para este grupo etário ${ }^{9-12}$. Um estudo de coorte, recentemente realizado no Centro de Atenção Integrada à Saúde da Mulher (CAISM), da Universidade Estadual de Campinas (UNICAMP), e publicado nesta revista, mostrou que em um universo de 2.400 partos de adolescentes, a frequência de BPN foi 15,1\% maior do que o esperado para a população geral e para a taxa geral do Serviço (que está aproximadamente a $10,0 \%)^{13}$.

$\mathrm{O}$ fato de a ausência de fatores reconhecidamente associados ao BPN não estar presente entre as adolescentes desta coorte (como hipertensão arterial, anemia ou tabagismo) reforça a tese de que o aumento de sua incidência nessa população seja de natureza multifatorial ${ }^{13}$. Outro estudo também demonstrou mais que o dobro da frequência de BPN em comparação a mulheres adultas, e mortalidade neonatal quase três vezes maior (além do risco de maior morbidade no primeiro ano de vida) ${ }^{10}$. Ao contrário dos estudos mencionados, há, no entanto, pesquisas nas quais ao se afastar ou se controlar a influência de fatores psicossociais desfavoráveis, antecedentes gestacionais de risco, exposição ao fumo e cuidados inadequados de pré-natal, a gravidez na adolescência não representa maior risco para ocorrência de BPN ${ }^{12}$.

A repetição gestacional, fenômeno cada vez mais relatado durante a adolescência, está se configurando como assustadora realidade neste país. No CAISM, em 2007, 15,3\% das gestantes atendidas eram multigrávidas, taxas que não têm recuado nos últimos anos, mantendo-se neste patamar altíssimo, considerando o grupo etário. Essas meninas apresentam pior escolaridade, menor adesão ao serviço de pré-natal, menor ganho ponderal, intervalo interpartal mais curto, menos estabilidade das uniões em geral precárias, quando comparadas com adultas ou mesmo pacientes da mesma idade em sua estreia funcional ${ }^{13}$. Em relação às complicações médicas, as multíparas adolescentes apresentaram risco duas vezes maior para recém-nascidos pequenos para a idade gestacional (PIG) do que para nulíparas adultas.

Quanto à parturição, como processo, alguns autores referem maior porcentagem de operações cesarianas motivadas por situações que se vinculariam ao processo de amadurecimento incompleto no crescimento e no desenvolvimento da mãe. Distocias funcionais, em estreias precoce e antecipada, bacia incompletamente formada, comportamento emocional descontrolado durante o trabalho de parto, apresentação e posições fetais anômalas e patologias mais incidentes justificariam mais cirurgias para ultimar o parto. Entretanto, não existem evidências estatísticas que demonstrem estar aumentado o número de cesarianas no grupo de modo especial e, ao contrário, inúmeros dados mostram uma tendência (não significativa) de taxas até mesmo inferiores às relatadas para todas as idades. Dados do SUS de 1997 demonstram taxas de 32,0\% entre adolescentes, duas vezes mais alta do que aquela recomendada pela OMS, como ideal. Porém, tais números devem ser interpretados sob a óptica da injustificável epidemia de cesarianas que grassa no Brasil na última década, claramente não associada à idade materna no momento do parto. A operação cesariana deve ter sua indicação judiciosamente ponderada como instrumento para a terminação do parto, quando se considera o formidável impacto de cirurgias sobre os futuros reprodutivo e obstétrico das jovens mães. 
Após o parto, persistem as dificuldades e até aumentam as necessidades e a complexidade do problema. As mortalidades materna e infantil estariam superiores de modo localizado no grupo de mulheres mais pobres e com mais baixo nível educacional, no qual predominam a escassez de recursos pessoais e financeiros e os adequados equipamentos sociais de suporte para o exercício da maternidade.

Apesar da manifesta liberalização das atitudes, dos comportamentos e dos costumes nas últimas décadas, a questão continua como fonte de problemas e tensões para os adolescentes, para seu círculo familiar imediato e para a sociedade como um todo. Independentemente do meio social ou cultural em que ocorra, a gravidez desempenha papel fundamental nas futuras oportunidades de inserção social, precipitando e ampliando uma série de acontecimentos que se combinam para desorganizar a harmonia do desenvolvimento pessoal e de seu núcleo familiar.

A eloquência indisfarçável dos números e das estatísticas que ainda persistem não deixa dúvida sobre a necessidade de se definirem planos e estratégias de abordagem ao problema, independentemente das pendências e controvérsias que subsistem às discussões.

\section{Referências}

1. Pinto e Silva. Gravidez na adolescência: uma visão multidisciplinar cap. 39 427-34. In: Saito MI, Silva LEV, Leal MM. Adolescência: prevenção e risco. 2 ed. São Paulo: Atheneu; 2008.

2. Presler-Marshall E, Jones N. Charting the future: empowering girls to prevent early pregnancy. London: Overseas Development Institute; 2012.

3. UN Inter agency Group for Child Mortality Estimation. Levels \& trends in child mortality: Report 2011. New York: United Nations Children's Fund; 2011.

4. World Health Organization [Internet]. Adolescent pregnancy: fact sheet. 2012 [cited 2012 Jun 12]. Available from: http://www.who.int/ mediacentre/factsheets/fs364/en/index.html

5. Martin JA, Hamilton BE, Ventura SJ, Osterman MK, Kirmeyer S, Mathews TJ, et al. Births: final data for 2009. Nat Vital Stat Rep [Internet]. 2011 [cited 2012 Jan 9];60(1). Available from: http://www.cdc.gov/nchs/data/nvsr/nvsr60/nvsr60_01.pdf

6. Brasil. Ministério da Saúde [Internet]. Brasil acelera redução da gravidez na adolescência. 2010 [cited 2011 Nov 6]. Available from: http:// portal.saude.gov.br/portal/aplicacoes/noticias/default.cfm?pg=dspDetalheNoticia\&id_area=124\&CO_NOTICIA=11137

7. Lloyd CB; US National Research Council. Growing up global: the changing transitions to adulthood in developing countries. Washington (DC): National Academies Press; 2005.

8. Molina Cartes R, González Araya E. Teenage pregnancy. Endocr Dev. 2012;22:302-31.

9. Ekwo EE, Moawad A. Maternal age and preterm births in a black population. Paediatr Perinat Epidemiol. 2000;14(2): 145-51.

10. Hoque M, Hoque S. Comparison of perinatal and obstetrics outcomes among early adolescents, late adolescents and adult pregnant women from rural South Africa. East Afr J Public Health. 2010;7(2):171-6.

11. Aquino-Cunha M, Queiroz-Andrade M, Tavares-Neto J, Andrade T. Pregnancy in adolescence: relation to low birth weight. Rev Bras Ginecol Obstet. 2002;24(8):513-9

12. Amaya J, Borrero C, Ucrós S. Estudio analítico del resultado del embarazo em adolescentes y mujeres de 20 a 29 años en Bogotá. Rev Colomb Obstet Ginecol. 2005;56(3):216-24.

13. Surita FGC, Suarez MBB, Siani S, Pinto e Silva JL. Factors associated with low birth weight among adolescents in the Brazil Southeast Region. Rev Bras Ginecol Obstet. 2011 ;33(10):286-91. 